\title{
AMENDMENTS
}

\section{Author Correction: Puma and p21 represent cooperating checkpoints limiting self-renewal and chromosomal instability of somatic stem cells in response to telomere dysfunction}

Tobias Sperka, Zhangfa Song, Yohei Morita, Kodandaramireddy Nalapareddy, Luis Miguel Guachalla, André Lechel, Yvonne Begus-Nahrmann, Martin D. Burkhalter, Monika Mach, Falk Schlaudraff, Birgit Liss, Zhenyu Ju,

Michael R. Speicher and K. Lenhard Rudolph

Correction to: Nature Cell Biology https://doi.org/10.1038/ncb2388, published online 4 December 2011

In the version of this Letter originally published, in Fig. 4f, the $P$ value for shRNA p21-2 infected HSCs versus control shRNA-infected HSCs from mTerc ${ }^{+/+}$, Puma ${ }^{-1-}$ mice is 0.04 and not non-significant (ns) as indicated in the figure. In the legend for Supplementary Fig. 2e, the correct $n$ values were $n=16-38$ mice per group (16 WT, $16 \mathrm{Puma}^{-/-}, 31 \mathrm{G}^{2} \mathrm{mTerc}^{-/-} \mathrm{Puma}^{+/+}, 38 \mathrm{G}^{3} \mathrm{mTerc}^{-/-} \mathrm{Puma}^{-/-}$) for the analysis of aberrant crypt foci (ACF) and $n=7$ mice per group for the analysis of macroscopic tumours. These numbers were swapped in the original figure legend. These two errors do not affect the conclusion or any statement of the publication.

Original

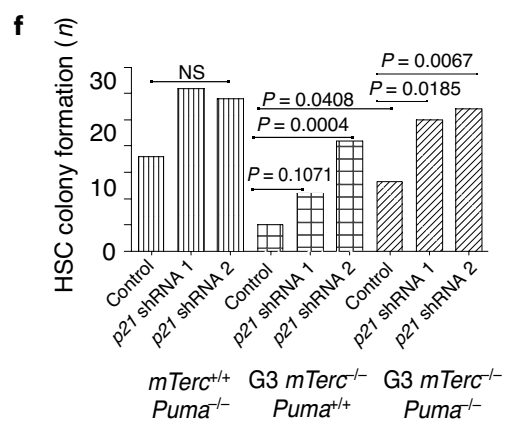

Corrected

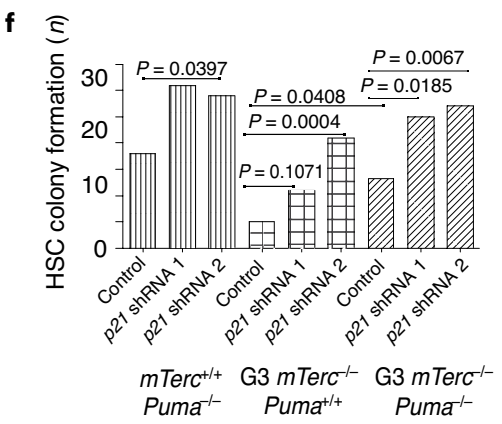

Fig. 4 | Original and Corrected.

\section{Additional information}

Supplementary information The online version contains supplementary material available at https://doi.org/10.1038/s41556-021-00633-w.

Published online: 28 January 2021

https://doi.org/10.1038/s41556-021-00633-w

(c) The Author(s), under exclusive licence to Springer Nature Limited 2021 